\title{
The Effect of Difference of Visual Stimuli in Photo Sharing Websites (Instagram) on Cognitive Achievement for Secondary Students in the Curriculum of Computer and Information Technology
}

\author{
Hussain Hadi Al-Harbi ${ }^{1}$ \\ ${ }^{1}$ King Abdulaziz University, Jeddah, KSA. \\ Correspondence: Hussain Hadi Al-Harbi, King Abdulaziz University, Jeddah, KSA.
}

Received: November 27, 2015

Accepted: December 14, 2015

Online Published: September 10, 2017

doi:10.5430/irhe.v2n3p34

URL: https://doi.org/10.5430/irhe.v2n3p34

\begin{abstract}
The study aims to clarify the effect of the difference of visual stimuli in Photo Sharing websites (Instagram) on cognitive achievement for secondary education students in computer and information technology curriculum through the answer of the following question: What is the effect different visual stimuli in PSW (Instagram) on the cognitive achievement for secondary education students in the computer and information technology curriculum? To answer this question, two different accounts in Instagram were signed up: the first account's subject was visual stimuli (Real Visual Stimuli) and the second's was visual stimuli (Graphical Visual Stimuli). The sample was (60) students of Al-Hateem Secondary School in Jeddah. The sample has been divided into two homogeneous groups. The first has been taught using RVS, and the second has been taught using GVS. A research tool (achievement test) has been applied for the experimental groups after the confirmation of validity and reliability of the achievement test.
\end{abstract}

Keywords: Visual Stimuli, Real Visual Stimuli (RVS), Graphical Visual Stimuli (GVS), Photo Sharing Websites (PSW), Instagram, Cognitive Achievement

\section{Introduction}

Education opportunities increase by visual stimuli due to the rapid development in the field of communications and information. One of the said visual stimuli is the photo-sharing websites, through which information can be rapidly transferred, where educational systems become in need of new thinking and modern strategies, in order to prepare a generation with skills necessary to deal with the current century variables and requirements.

Thus, the education institutions try to provide the students with a high level of competence and skill, through self-education and keeping pace in all fields (Dosougi, 2006, p. 474).

Educators paid attention to meeting diverse educational needs through the development of educational systems, and utilization of the modern technologies in order to find possible solutions to the posed problems, and the best ways providing suitable learning environment.

Social networking is one of the modern forms of the Internet, second-generation applications, Web 2.0, which allows interaction and communication between users. The above applications are represented by the Facebook, Twitter, YouTube, Blogs, Instagram, and Flickr and others.

Al-Amoudi (2009) thinks that these applications enable users to build new relationships with others, share them the "intellectual, cognitive feedback, and hobbies" and disseminating the whole via the multimedia including the text, sound, photo and video- the technologies that representing the next generation important attributes. All the applications listed rely primarily on visual stimuli.

Most articles discussing the visual stimuli indicate the acute need to increasingly use the visual materials in education; this is obviously noticed from frequent use of optics in all aspects of life, and the emergence of the same in the field of education (Abdul-Hadi and Abdul-Rahman, 2004, p. 8).

Whereas visual stimuli (real photo, graph) constitute the most important means expressing the facts and ideas interestingly and impressively that contributes to student learning well, where those stimuli could be efficiently utilized, focusing on the most appropriate and common mean that provides learners with the necessary learning materials efficiently. 
(Paivio 2006) who wrote "the dual coding theory" thinks that the memory is divided into two types: one of them is to represent the verbal information, and the other to represent the non-verbal information, the encoding of which in both memories leads to a level of remembering better than encoding of one memory, and this method supports learning when visual stimuli used.

Instagram is one of the photo-sharing sites and one of the Web most famous applications Web 2.0, which basically depends on the use of visual stimuli realism, both real and graph. It is a free application for photo and videos sharing, as well as social network, where web photo allows discussion to a number of diverse learners who are interacting about these photo and encourage others to publish other photos related to the same basic sharing subject, it is rather, host digital photos for the learners willing to share them over the Web. Every learner is allowed to download photos and add comments \& different explanations about these photos, and establish \& manage his own set of photos through using the social context to share other learners.

The visual stimuli including the photo sharing sites, constitute the way by which the emerging younger generations think, and that adherence to traditional methods of education will lead to a gap and a sharp separation between what is delivered to students in educational institutions, and ways of thinking in the outside world, so it is necessary to educators to take advantage of these visual stimuli to have educational that adapted to the around as awhole (Klopfer, Osterweil, Groff, and Haas, 2009).

According to the previously mentioned points, it obviously that the importance of utilizing the poto-sharing sites in both teaching and learning processes enforce the educational institutions to adopt strategies and teaching aids allow optimal utilization of visual stimuli through photo-sharing sites.

Due to the growing turnout and the interaction between users, the researcher tries to utilize photo-sharing sites in education through Instagram site and take advantage of these presentations and try recognizing the visual stimulus which help students understanding interestingly and effectively.

\section{Problem}

Under the Web-second generation applications, the importance of using photo-sharing sites rises in both teaching and learning process, which is a new reality utilized in the educational process. In this study, the researcher tries to recognize the right part, in order to utilize such sites that depend on the idea of showing digital photos-sharing sites, but said photos have many types, including real photo and graph, the real one have many characteristics, some of which, is that they simplify reality and focus on the basic details of the photo excluding unimportant details, but recognizing the preference one type in comparison to another together with utilizing the same in the teaching the high level Computer and Information Technology curriculum can only take place through scientific research.

Some studies findings have pointed to the effectiveness and essence necessary to utilizing the visual stimuli in both teaching and learning processes such as Fath Allah (2007) and (Stavy, 2008) study, in addition, (Tibell, 2010) study discovers the effectiveness of using visual stimuli real photo using animated and still photos in teaching science subject to the high school students, where the findings showed the effectiveness of visual stimuli- real photo regardless of its kind in the students' achievement and trends.

But the studies paid attention to the effectiveness of the graphic photos as opposed to traditional education and the impact of which on student achievement (Grabowski study, 2004)), which aims at identifying the impact of the diversity of visual stimuli photos - the fixed graphical photo in comparison to the animation on the student's achievement and performance. The study reveals that there are no differences related to the diversity of visual stimuli in achievement and performance, in addition to (Hughes study, 2007), which targeted the impact of the graphic photos through animation on student achievement, and the findings showed superiority by the group of education (through the graphical photos) over the traditional education group (in the field of achievement).

From these studies, it is obviously that they focus on the comparison between the two types: real photo and graphic photo to discover which are more effective, and in (Al-Sarraf study, 1998) that targeted the recognition of the effect of the real photo as opposed to graphic photos, the findings showed that the real photos are more preferred by learners unlike the graphic photos, whereas in (Khalaf Allah study, 2010) which targeted the recognition of the effectiveness of different real photo in comparison to the graphic photos, the findings showed that the graphic photos are more effective than real photo.

Such studies conducted the comparison process in other environments other than the photo-sharing sites. In this research, such as (Fath Allah study 2007), conducted through educational activities, or (Khalaf Allah, 2010), which took place through a proposed program, or (Erigin, 2008)) and (Stavy study, 2008), which took place through photos presentation via computer. 
Even in these studies framework, which paid attention to a comparison between the types of photos using different environments, we find that they focused mostly on the comparison between still photos and animation (Grabowski study, 2004)) and (Tibell study, 2010), then they thought in conducting study to compare between real photo and graphic photo, but in a different and modern environment -photo sharing sites.

(Al-Halfawi 2009) has pointed out to the importance of relying on photos sharing sites in delivering some curriculum that can be delivered through these environments.

In a study conducted by (Waycott and Kennedy, 2009, pp. 1085-1095) targeted the recognition of the effectiveness of using photo sharing tool as one of the Web applications 2.0 in the teaching chemistry at the University of Melbourne, Australia, where the experiment was based on the use by educators to their mobile phones in photocopying some chemical phenomena that occur in everyday life, and then disseminating the same in the Web through Flicker, as one of the photo sharing sites and exchanging discussion about those photos. The study finding emphasizes that the sharing of the photos enabled the students to see many phenomena and recognize some details that are difficult to be achieved in conventional methods. the study sample of students has upload (1894), of which (1849) photos of which were subjected to comment, and the total comments is(4262), which demonstrates the attraction of the students towards the photo sharing tool among educational topics study.

Nov and Ye (2008, pp. 1-11)study that everyone has a set of self motives that encourage him to share photos through different locations, which indicates that the learners of the current generation have what may help to adopt Photos sharing in the learning processes idea.

For the attention paid to photo sharing among the learners, (Kucuktunc, et, al study, 2008, pp. 61-73) targeted building a system integrating between photos and texts to increase the effectiveness of learning process, where the study has developed a system that allows the learner to raise upload his photos, together with posing a description or explanation to these photos in the system, whereas this description is compared to the system database, and in turn it is essential to display all photos associated with this text description that the learner uploaded through the system, the matter making retrieval process easy to enrich learner.

Accordingly, the research problem can be formulated in the following question:

What is the impact of different visual stimuli in the photo sharing sites Instagram on the computer and information technology cognitive achievement development by the high school students?

\section{Objective of the Research}

Identification of the suitable visual stimuli (real - graphical) in the photo sharing sites Instagram photos on the computer and information technology cognitive achievement by the high school students.

\section{The Need of Research}

The research is highly important due to:

4.1 Identifying the appropriate visual stimuli (real - graphical) in the delivery of computer and information technology curriculum through photos sharing Instagram sites.

4.2 The research is an attempt to utilize visual stimuli in sharing photos sites to urge teachers and students alike in using Instagram in both teaching and learning processes.

4.3 The research represents a response to the previous studies that recommend taking advantage of the features and potential found in modern applications Web 2.0 (Al-Khalifa, 2006); (Weller and Dalziel, 2007, pp. 1-7); (First International Conference of e-learning and distance education, learning industry, Saudi Arabia Industry, 2009).

\section{Research Hypotheses}

There are significant statistically differences at 0.05 level between both mean scores of the cognitive achievement test for the experimental group (real stimuli) and the second experimental group (graphical stimuli) due to the impact of different visual stimuli in the photos sharing Instagram sites.

\section{Methodology}

\subsection{Participants}

Research group consisted of 60 students from the first grade high school students, who are randomly selected and divided into two groups, each group consists of 30 students, according to the following table: 


\subsection{Experimental Design}

The current research uses a semi-experimental method to recognize the impact of different visual stimuli (real graphical) Instagram on the high school students cognitive achievement in the computer and information technology curriculum by both groups of research.

Table 1. Experimental design research

\begin{tabular}{lll}
\hline Independent variable & \multicolumn{2}{c}{ Visual stimuli } \\
\cline { 2 - 3 } & Real & Graphic \\
\hline Groups & First group (m1) & Second group (m2) \\
\hline Dependant variable & Cognitive achievement & \\
\hline
\end{tabular}

\subsection{Independent Variables}

The research includes two variables:

6.3.1 Independent Variable: both types of visual stimuli (real - graphical).

6.3.2 Dependent Variable: high school first class students' cognitive achievement in Computer and Information Technology.

\section{Literature and Theoretical Review}

\subsection{The First Aspect: Visual Stimuli}

\subsubsection{The Concept of Visual Stimuli}

Introduced by Abdel Moneim (1999, p. 66) all the matters with which the learner deals through sight, except the verbal written language.

Hamid (2004, p. 111) think that they represent a set of visual aids represented by lines, words photos, graphs, photographed materials, , posters, which express the ideas, facts, and relationships in a plain visual photo with which the learner deal through his perception.

Accordingly, the visual stimuli are real or digital graphical photos expressing the reality with all details or through summarizing some of its elements to serve specific educational purposes, and those are produced either through the direct digital imaging or programming the same from the paper form to digital form.

\subsubsection{Types of Visual Stimuli}

\section{A- Real Visual Stimuli}

Khalaf (2010, p. 11) introduced it as all what address the sight including photos and things representing a real embodiment to the reality of learners without nature or component change.

The real visual stimuli represent the display of life real natural elements to bring that to the mind of the learner, such as photographing living organisms or landscapes, and so and provide the same to the learners, they express reality using photos, and those stimuli could be utilized in the courses, in addition to usage in the presentation of real things needed by some courses, the absence of which from the learner's mind, may lead to incomprehension.

It means that the visual stimuli are photos "providing learners with the reality without any change".

\section{B- Graphical Visual Stimuli}

Khalaf (2010, p. 11) defines it as a set of animations, still photos, graphics, and brides describing the imagination which used as a mean expressing the skill or idea that suit the pupils.

Graphical visual stimuli represent a "set of photos that simplify reality and focus on the key elements to help the learner understanding and recognizing the facts more effectively."

Othman and Othman (1994, p. 185) indicate that the graphical visual stimuli are important due to many factors as follows:

(1) The visual stimuli have strength and exciting by which they attract the attention of students unlike all other means. 
(2) It is a preferable mean of communication and make students paying attention, therefore their usage in the field of education enriches the educational field.

(3) Representing the abstract reality that is difficult to be perceived through senses, and animation can interpret the graphical scientific facts to be easily perceived.

(4) Such stimuli characterized with vast imagination which are not restricted by the known natural laws.

(5) Simplifying the events and comic things to be rigid reality, and the potential simplicity make such stimuli as a tool that is necessary to the interesting scientific, technical and social topics to be accepted by young and old.

(6) They are used to facilitate some difficult topics to highlight the defects or for the avoidance of obstacles that in the absence of any other solution.

(7) The stimuli represents a tool to help explain the complicated sciences and phenomena such as the functional relationships between components.

(8) Making learners interested.

(9) Provides rare experiences, efficient and diversified learning

\subsubsection{The Importance of Visual Stimuli}

Visual stimuli are important due to their vital role in the translation of verbal ideas, overcoming of difficulties to understand the abstract information, and convert verbal educational content into easy content through various visual stimuli (Shibl et al., 2013, p. 14).

The visual stimuli may be of vital role in the learning process as Hamid indicates (2004, p. 148) as follows:

(1) Students experience attention and concentration.

(2) Increasing motivation among students due to the availability thrill element.

(3) Help to understand the ideas, abstract concepts, through the translation of those ideas and concepts visually.

(4) Having proper meanings to the abstract phrases and ambiguous names less errors on the least time.

(5) Sincere impressions that reach the minds of pupils together with surviving learning impact for a long time.

(6) Making the student more willing to learn.

(7) Provides a lot of sensory experiences that represent basis in the formation of sincere perceptions.

Mixer, et, al 2008 pointed out to the importance of the utilizating the visual stimuli in the provision of educational material for students by describing how to use visual stimuli as a tool to improve student learning; and (Schlosser, 2008) think that visual stimuli play a crucial role in the integration and the use of Teaching techniques.

\subsubsection{Educational Design of Visual Stimuli}

The educational Design is one of the main processes for Educational Technologies, and the beating heart of any educational program. The principles of educational design as a whole constitute a turning point rather than being an application on the web, to become an educational application achieving educational goals that are precisely prepared and defined by the educational designer.

In the light of the system theory, educational techniques pay attention to the design field of teaching and learning, in which views overlap through knowledge and curriculum Engineering- the structure that is designed around an organized and flexible principle on the the basis of scientific study, which utilize educational technology that is necessary to apply modern techniques of the relevant curriculum. One educational model do not fit all levels of education attitudes of teaching \& environment in addition to the future needs.

There are many forms that discuss the educational programs design as per their levels in terms of comprehensiveness, depth, objective nature, targeted learning findings and learning mastery. All these taken place in accordance with the learning theories that depend on the educational strategies aiming to application in different techniques to realize educational purposes and objectives that represent the learning maps main structure.

Yeh "2008" indicates that the current educational designers prefer including the visual stimuli in the educational products, in order to help learners to understand the academic content better; due to the findings of scientific studies that the visual stimuli in addition to text can improve learning through providing more enriched learning environment. 
For researchers to design the visual stimuli properly, it requires a great deal of knowledge and skill with regard to the principles of the visual stimuli educational design.

\subsubsection{Visual Stimuli Educational Design Principle}

They are principles and guidelines derived by specialists to guide the effective design process of the visual materials ((Yeh, 2008, p. 10).

Both Abdel-Monem (1999, p. 41), Shawgi (2007, p. 38), Shibl et al. (2013, p. 26) pose a set of visual stimuli design principles as follows:

(1) Simplicity

It has a relation with Pragnanz that means accuracy and one of the Gestalt laws which states that the cognitive organization tends to move towards only one general trend (good form) which is characterized by regularity, completeness, simplicity, accuracy and other meanings, and in turn, form will be the best.

\section{(2) Clarity}

It means the visual acuity with which we see things according to their farness or proximity, that the near objects can clearly show their details, unlike the distant objects that are difficult to be seen by us.

(3) Organization

Whereas non-organized stimuli are known to be difficult to understand and remember, the system is highlighted is an integrated entity, which consists of overlapping parts and elements between which exchangeable relations are established, then the system is realized.

(4) Context should be taken in account

Stimuli general pattern within the visual scene, which is one of the factors that influence the shape perception.

(5) Background and shape should be taken into account

It is one of the main regulatory steps in the perceptual process, responsible for the separation of the visual field in the form of shape and base, for example, you choose the important shapes in any photo and make more attention compared to the background, so that the designer makes the fundamental information shapes in order to attract the attention and become dominant.

\section{(6) Balance}

It regards the elements status and stability within the composition of shape, and balance may be formal depending on the visual stimuli shapes, area, weight, and the method of distribution in the shape base, but balance may not formal.

(7) Similarity

Indicates the similarity degree between stimuli (stimuli popularization, in which there is a response to a new stimuli same as the previous one, and the degree of similarity between the responses (response popularization) requires that stimuli remain the same (identical) in both cases of learning.

(8) Reliability

Stability is related to the interaction front as there are factors influencing the shape stability such as the duration of vision, and to which extend attention is high because flash vision to the shape without high attention makes our understanding confused and inaccurate, but adequate vision that allows the device collecting various information about the shape and its components, accompanied by high attention, will produce true perception to shape and its components, it also helps the optical device to correct the shape.

(9) Using hints and signals (education keys)

Such as using arrows, putting lines under important points or putting circles and rectangles around those points, where the use of these keys and signals makes the learners paying high attention.

Based on what is mentioned, and to realize these principles effectively in the visual stimuli, it is necessary to take into account the principles of good design, select the visual stimuli relevant to student interesting and focus on the photo content and harmony with the instructional message.

\subsubsection{Visual Stimuli Selection Criteria in Education}

Both Abdul-Hadi Abdul-Rahman (2004, p. 11), Khalaf (2010, p. 22) indicate that hereunder a number of criteria that must be taken into account by teacher before selecting any photo: 
A. gravity: the selected visual stimuli content should attract the pupils' attention.

B. The selected stimuli relation with the lesson: the selected visual stimuli should be related to the lesson in relation with the lesson topic.

C. Easy discrimination: students are able to understand the meanings expressed by visual stimuli, it means that each learner can interpret the message that we intend to deliver to him by those stimuli, but the selected stimuli and their components should be in the framework of pupils' information and culture.

D. Visual stimuli good utilization: it is preferable to utilize the visual stimuli and not to make it busy through lesson, or propagate the same without the need as this may disperse the attention of students with no attention in the stimuli content.

E. Displaying the visual stimuli on time: it is preferable to use visual stimuli in the students' education on timely manner, to display the same either before, during or after lesson.

As the visual stimuli are important, they were discussed by some studies and research that indicated the effectiveness and the need to utilize them in both teaching and learning processes such as (Fath Allah study 2007), (Stavy, 2008), and some of which focused on the visual stimuli discussed the effectiveness of real photo separately and graphical photos as well. One of those studies focusing on real photos as opposed to traditional education and the relevant impact on student achievement is that wrote by (Yusuf study 2006) which targeted the recognition of the different visual stimuli density (real - graphic) and the method of delivery to develop the computer programs production skill by the education technology department student at the faculty of education, the findings showed the effectiveness of visual stimuli intensity in the achievement regardless of the visual stimulus type, and (Tibell study, 2010) which targeted the effectiveness of the use of stimuli visual real photos using animation and still photos in the teaching science to high school students, where the findings showed the effectiveness of stimuli real photo regardless of their type in the students achievement and trend.

But the studies focusing on effectiveness of graphic photos as opposed to traditional education and its impact on the student achievement are (Grabowski study, 2004)), which aimed at identifying the impact of the diversity of visual stimuli graphical-still photo, in comparison to the animation on the students achievement and performance, the study found no differences due to the diversity of visual stimuli in achievement and performance, and the study prepared by (Hughes, 2007)), which targeted the impact of the recognition of the graphic photos through animation on student achievement. The findings showed the superiority of education group through the graphical photo over the traditional education group in terms of achievement.

It is noticeable from these studies we find that they focus on the comparison between the two types- real photo and graphic photos which is more effective, and in (Al-Sarraf study, 1998) that targeted the recognition of the impact of real photo as opposed to graphic photos, the findings showed that the real photo are preferable among students unlike the graphic photos, while (Khalaf study 2010) which targeted the recognition of the effectiveness of different real photo in comparison to the graphic photos, the findings showed that the graphic photos are more effective than real photo.

As these studies conducted the comparison process in other environments other than the environments of sharing photo sites this research, such as (Fath Allah study 2007), which was through educational activities, or (Khalaf study 2010), that took place through a proposed program, or (Erigin study, 2008)) and (Stavy study, 2008)took place through the presentation of photos via computer.

Under framework of these studies focusing on a comparison between the types of photos, and using different environments, it was obviously that they focused mostly on the comparison between still photos and animation such as (Grabowski study, 2004)) and (Tibell study, 2010), then they thought to conduct a study to compare between real photo and graphic photo, but in a different environment - photo-sharing sites.

\subsection{The Second Aspect: Photos Sharing Sites}

\subsubsection{Photos Sharing Sites Concept}

They are Web pages including a group of digital photos with logic relations to be published through the Web and provide the same using different tools and ways for interaction. Instagram is a site for photo shows that allows sharing photos, where is used as a host to the digital photos for whom willing to share them over the Web. Moreover, it allows every user to download photos desired through the website and add different comments and explanations about the photos. Nevertheless, every user can establish and manage its own set of photos sharing the same among social context (Al-Halfawi, 2009, p. 34). 
Accordingly, represent Web sites allow the publishing of classified groups of digital photos accompanied by additional comments and explanations as well as a set of tools that allow interaction with these photos."

\subsubsection{Photos Sharing Sites Importance}

The contemporary challenges impose utilizing the modern technologies in teaching and learning activities, one of which is the enormous information flow formed the knowledge society, and in turn there was a need to link and integrate the services between technology, information, communication and media, and in the past, the learner travels long distance to get information, While at the moment there is an abundance and flow of information.

One of these modern techniques the photo sharing sites where it can be relied upon in a variety of educational situations, where the learner is provided with a variety of photos act also as an educational materials helping the learner to study different content and topics, in addition to some sites allow you to interact with the same photo by focusing on certain parts of the photo by adding some geometric shapes or changing some of the colors of the photo, which is called interactive graphics with the photo and adds fun tothe learning process. In addition, it is highlighted as a tool for continuous support to the learner (Al-Halfawi 2009, pp. 34-35), Cobb, 2008, pp. 51-52)).

\subsubsection{The Most Important Photo-Sharing Sites}

Photo-sharing sites are not just for meeting new friends, but it is an amazing educational tool information source if used efficiently. It can also be used in both teaching and learning activities in order to improve communication, and integrate students in efficient activities different from the traditional teaching styles, students also recognize the most useful photos sharing sites. Most important of these sites, as referred to by both (Steiner, Gabarró, and Hausenblas, 2009 pp. 49-51), (Ra, Govindan and Ortega, 2009 pp. 515-528) as follows:

1- (Instagram): free application to the photos sharing, video clips and the social network, it also allows users to pick the photo adding to which, a digital filter, in addition to the possibility of sharing with a variety of social networking services such as Face book, Twitter, Flickr and Google+, which was established in October 2010 and purchased by Face book April 2012.

2- Flicker: photo and video sharing site, in addition to saving and arrangement. It represents an association of amateur photographers on the Internet. In addition, the site is used by bloggers through the re-using of the photos. The said site won its fame through its innovations such as comments addition by visitors and tags. On September 2010, it was decided to host more than five billion photos, it was established on February 2004 and bought by Yahoo March 2005.

3- Imgly: a server that is necessary to host photos and was established in 2009 , through which it is possible to share photos on Twitter.

4- Imgur: a server that is necessary to host photos and was established in 2009 , through which it is possible to share photos on Twitter and Face book.

5- Photobucket: it was established in 2003 to host photos and videos, in 2011, Twitter announced the exclusive partnership with the site to be as a platform for photos exchange.

\section{Instagram}

Free service for photo-sharing, video clips and social network, it allows users to pick photo, and add a digital filter, in addition to the possibility to share the same with a variety of social networking services such as Facebook, and Twitter, Flicker, and Google+, it was established on October 2010, and the number of subscribers reached 30 million only within two years (more than one million subscribers loaded this application only within 12 hour. Face book on April 2012, purchased the company for US \$ one billion (Steiner, et, al 2009 pp. 52).

\subsection{Instagram Characteristics}

It referred to as the "Computer and Information Technology" 2015:

8.1.1 Dealing with different types of cameras, together with the front and back camera support.

8.1.2 Free-use to all features related to photo sharing and processing.

8.1.3 Provides various tools for photo processing with friends on various social networks such as Face book, Twitter, Flickr, (Google+), and (Tumblr).

8.1.4 It is possible to block the account making it as special to host special people.

8.1.5 It can be used on devices that ran using the Android operating system (ios). 
8.1.6 It is possible to add and classify names and explanations on the photos. And it is allowable to add any comment directly on the photos with no need to go to the networking site.

8.1.7 The program applies the idea of tracing people whom photos suit you or that you have known and then see all their photos they automatically load.

8.1.8 Inserting photo search indication (hashtag), where hash means \#, that any search indication must be preceded by this sign and then the search word (Example: \#ROSE) accordingly this photo will join the search findings under this word).

\section{Procedures}

\subsection{Educational Design of the Photo-Sharing Sites "Instagram According to Mohammed Attiah Khamis Model}

Photo-sharing web design is not merely based on steps, but depends on instructional design of the learning environment on the Internet, as in the learning environment it is essential to take account to all the matters related to the educational process through the Instagram photos site such as putting objectives strictly in addition to analyze the needs and characteristics of the target audience rather than its capabilities and compatibility with learning material as well as the design of the learning environment, upon which level identification and teaching strategies could be determined, in addition to taking into account the technical side in the process of design and production in accordance with the principles and criteria (Fathi, 2006, p. 166).

\subsubsection{Analysis}

1. Problem analysis and needs assessment:

This takes place through studying the gap between the current and desired reality, which reveals the lack of skills, sentimental or cognitive aspects, so it is possible to benefit from the advantages of the photo-sharing Instagram sites in displaying the visual stimuli allowing the sharing of learners in building the learning contents, interaction and Social communication between learners and teachers, ease of use, and allowance of sharing between learners and many features that are non-existent in the traditional context.

2. Analysis to the learners characteristics and behavior: The determination of learners' academic, social and psychological characteristics helps in building and designing photo-sharing sites accurately.

3- Analysis of educational tasks: through using the two visual stimuli (real - graphical) in Instagram to support content using the photos and then the teacher participates by adding visual stimuli and provide feedback to learners.

4- Environment resources and constraints analysis: students can enter and use Instagram site where students can be provided with mobile devices including Instagram application.

\subsubsection{Design}

1. Educational goals design, analysis and classification: it is to specify the overall objective through using visual stimuli in Instagram as an increase to the knowledge achievement, learning sharing, and through studying the chosen two educational units- multimedia and robot, all educational goals are specified, and behaviorally formulated to help determine the educational content.

2. Referenced measurement instruments design: represented by the achievement test.

3. Content design and strategy of organization: In this step the scientific content elements are determined in light of the overall objectives and procedural objectives that predetermined.

4. Learning and education strategies design: the strategy followed in the use of visual stimuli (real - graphical) is a self-learning one where the first group deals with visual stimuli (real) and the second group deals with visual stimuli (graphical) under the guidance of the teacher, and through Instagram, the educational content is displayed to raise the learner's motivation.

5. Scientific interactions strategies scenario design: to determine the roles of the teacher and learners and learning resources, in addition to specify the form of the learning environment, where the photo sharing sites provide a learning environment that allows opportunities for interaction and sharing in building educational content. The learning resource in the photo-sharing sites involves the real and graphical stimuli.

6. Determining the learning appropriate style and pattern: There are many styles and patterns such as mass distance learning, small-group learning, individual independent learning adopted in the current research.

7. Multi-learning sources selection: the sources available within Instagram were selected to meet the learners' needs (visual stimuli). 


\subsubsection{Development}

1. Scenario preparation:

- Objective order and elements of content clearly.

- A brief and comprehensive description of content as per the order specified.

- Determine the content of visual stimuli (real - graphical).

- Determine the shape and quality how the visual stimuli.

- How the visual stimuli appear.

- Underlying the main ideas for each element as per the order

- Distribution of appropriate sources that have been identified in the last step of design.

- Determining the number and kind of pre-test and post-test questions.

2. Production Planning: this stage includes underlying the visual stimuli appropriate for both teaching and learning processes.

3. Development: obtaining the visual stimuli (real - graphical) that obtained by the researcher from the text book of computer and information technology by the ministry of education, and photos libraries available across the Web 2.0.

4. Constructional assessment processes: in such a case visual stimuli in Instagram subjected to the adjustments necessary to get the final production, which takes place through pilot experimentation on a sample of (10) students with characteristics that are close to the characteristics of the sample, and were randomly selected from the community in order to identify the extent of ease and difficulty of the use of stimuli in Instagram, and problems facing the learners during the use and the strengths and weaknesses.

The pilot experimentation findings discover the easy used of stimuli in Instagram, and in turn the application becomes ready for main experiment.

5. Final directing of visual stimuli and using the same in Instagram after making the necessary adjustments after the completion of constructional assessment, Figure 1 highlights the real stimuli, and Figure 2 highlights the graphical stimuli.

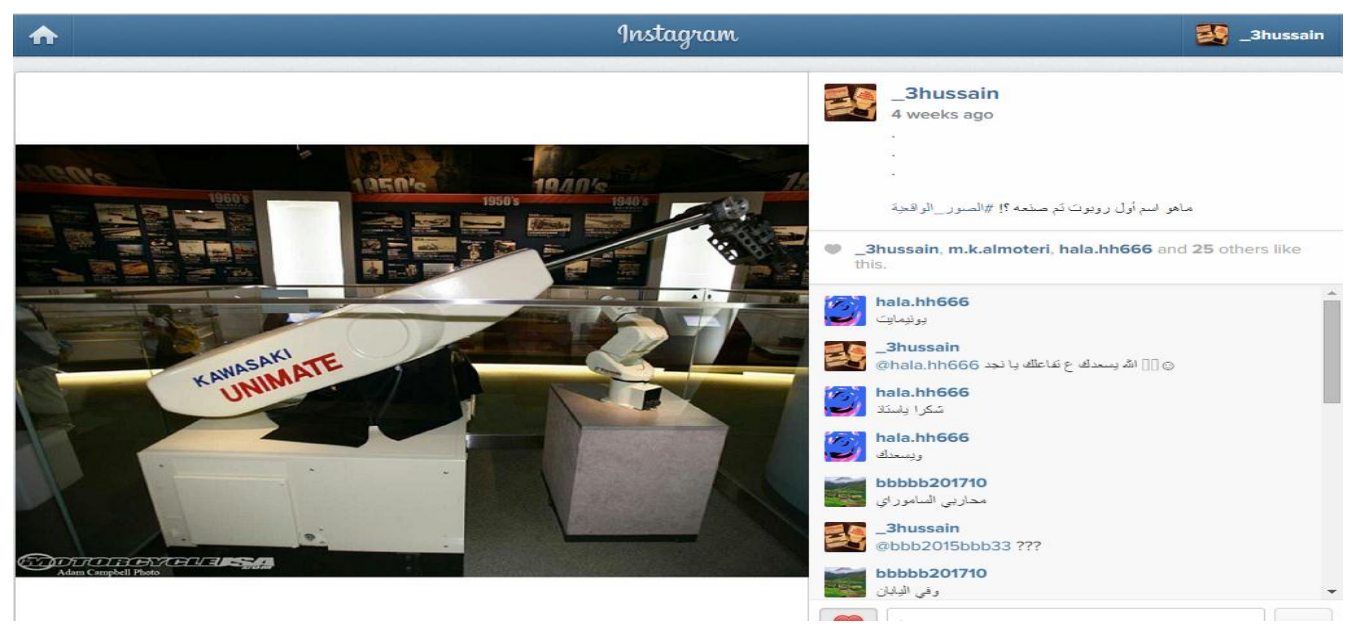




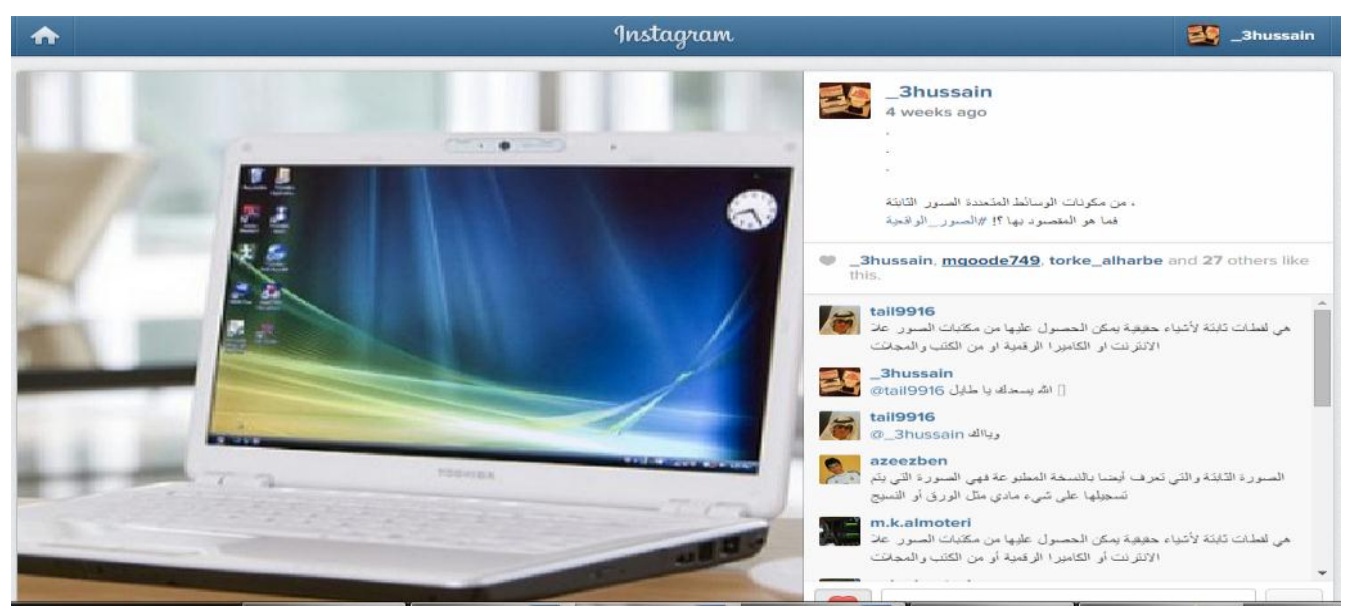

Figure 1. Real stimuli form
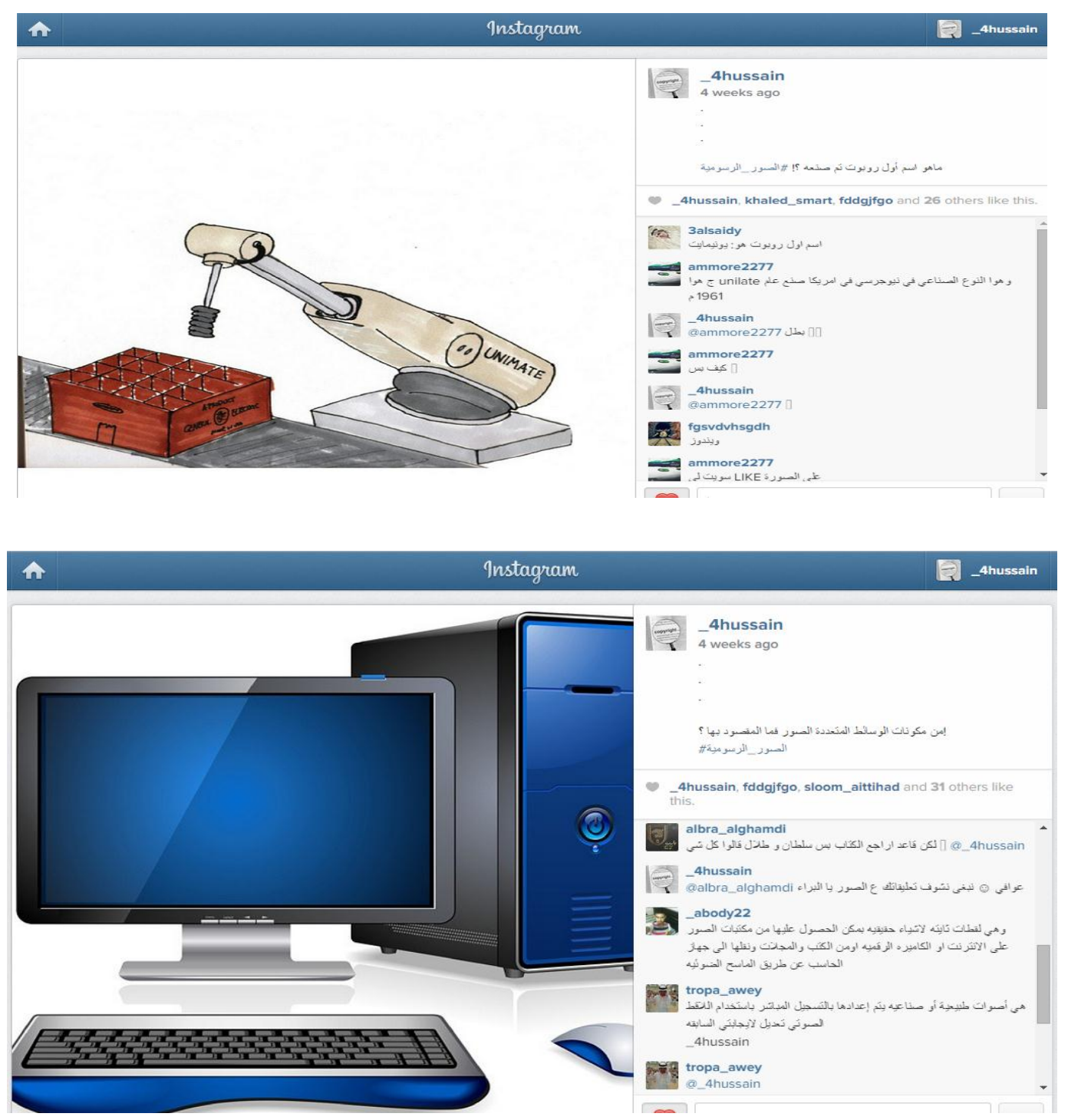

Figure 2. Graphical stimuli form 


\subsubsection{Final Assessment Stage}

The current study aims to identify the effectiveness of Instagram to achieve the desired educational goals, this stage has been executed in the current search through pilot experiment and the basic experiment.

\subsection{Research Tool Building}

- The test was prepared from (30) paragraphs by using two types of objective tests, namely, (multiple choice which consists of (22) paragraphs - true and false which consists of (8) paragraphs, and the achievement test was given to an pilot sample composed of (10) of Al-Hateem high school first grade in Jeddah. After that the calculation includes:

9.2.1 Determining the test time: After the test sample applied to the members of the pilot experiment, time spent in achievement test was estimated (35 minutes)

9.2.2 Easiness and difficulty coefficient calculation: through calculating the coefficient of easiness and difficulty, for each individual, the researcher discovered that the percentage of easiness percentages range from (0.31-0.62), and the difficulty coefficients ranged between (0.37-0.81) which means they are acceptable rates, and in the light of these findings, the Researcher rearrange vocabulary test in accordance with the easiness coefficients and difficulty where they fall from easy to difficult.

9.2.3 Test stability calculation: Spearman-Brown Spilt Half is used in order to find the correlation coefficient between both parts of single and double test from the the correlation equation, and the value of the test stability coefficient (0.85), a coefficient that can be trusted to reach Self-honesty (0.92).

\section{Pilot Study of Research}

The research tool was applied in advance to ensure the harmony and parity of the both experimental groups, then the researcher uses the significance test of differences between the averages " $\mathrm{T}$ " for the Independent samples T-Test in the statistical package related to social sciences program SPSS (22) to identify to which extent there is a homogeneity between the two groups through the pre-test of cognitive achievement findings.

The following table shows a summary of the findings of the statistical analysis to pre-test:

Table 2. Test findings, (T) Independent Samples T-test to independent samples that is necessary to study the significance of differences between the averages of the both experimental groups students in the pre-test.

\begin{tabular}{|c|c|c|c|c|c|c|}
\hline \multirow[t]{2}{*}{ Group } & \multirow[t]{2}{*}{ No } & \multirow[t]{2}{*}{ Mean } & \multirow{2}{*}{$\begin{array}{l}\text { Std. } \\
\text { Deviation }\end{array}$} & \multicolumn{3}{|c|}{ T-Test } \\
\hline & & & & Df & $\mathrm{T}$ & Significance \\
\hline $\begin{array}{l}\text { First pilot (real visual } \\
\text { stimuli }\end{array}$ & 30 & 16.80 & $5 . .241$ & 58 & 1.831 & 0.05 \\
\hline $\begin{array}{l}\text { Second pilot (graphic } \\
\text { visual stimuli }\end{array}$ & & & & & & \\
\hline
\end{tabular}

Under extrapolating the findings took from the previous table, we notice the value that the "T" was (1.831) at (58) degree of freedom and with capacity $(0.887)$, which is a significance level greater than $(0.05)$ which refers to the lack of statistically significant differences between the mean scores of both students groups in achievement of pre-test, which refers to equal levels of knowledge to the students before the experiment.

After completing the search experiment and both groups have been taught the Instagram in accordance with the open visual stimuli.

\section{Conclusions}

Hereunder the findings given by the statistical analysis:

Such findings are related to imposition termed "there are statistically significant differences at the level of 0.05 between the mean scores of the knowledge achievement between the first experimental group (real stimuli) and second experimental group (graphical stimuli) due to the impact of different visual stimuli in the photo sharing sites Instagram".

To test the validity of this hypothesis the of test significance of differences between the averages T-Test "Independent Sample" for independent samples in the statistical package for social sciences, SPSS program (22) to 
calculate the arithmetic mean, standard deviations, and then the value of " $\mathrm{T}$ " and its statistical significance between the mean scores of both experimental groups (real stimuli - graphical stimuli) in the cognitive achievement posttest. The following are the findings of Independent Samples T-test related to the sample individual degrees achievement posttest.

Table 3. Independent Samples T-Test findings (v) to study the significance of differences between the mean score of students in both experimental groups in the posttest

\begin{tabular}{lllllll}
\hline Group & No & Mean & Standard deviation & Df & T & Sig \\
\hline Real stimuli & 30 & 21.70 & 5.50 & 58 & 1.60 & $\begin{array}{l}\text { Non-statistically } \\
\text { significant at 0.05 }\end{array}$ \\
$\begin{array}{llllll}\text { Graphical } \\
\text { stimuli }\end{array}$ & 30 & 20.13 & 4.93 & & & \\
\hline
\end{tabular}

Under extrapolation of findings in the above table, it is clear that the value of " $\mathrm{T}$ " was (1.60) at (58) with significance level $(0.329)$ greater than $(0.05)$ which indicates that there is no statistically significant differences between the mean scores of both student group in the post application of cognitive achievement test.

Based on this finding researcher refused the research hypothesis where statistical findings indicated that "there is no statistically significant differences at the level of statistical significance (0.05) between the mean scores of the knowledge achievement test between the first experimental group (real stimuli) and the second group (graphical stimuli) due to the impact of different visual stimuli in the photo-sharing sites Instagram.

There are no statistically significant differences between the two groups of research in the post-achievement, due to the different visual stimuli (real - graphical) in Instagram for the following reasons:

(A) The nature of content delivery using visual stimuli (real - graphical) helped increasing the knowledge achievement through Instagram.

(B) Through the dual coding theory, visual stimuli deliver better education to students when they are prepared properly in a manner supports the delivery of the educational content, as those stimuli have a vital role in the formation of knowledge when they are of equally impact or they may differ in their power to attract the attention of the learner.

(C) Student could be attracted to the visual stimuli (real - graphical), in this regard, students have uploaded (144) photos of whic (120) found comment, with total comments (508), the matter improved learning levels, and attract the attention of students.

(D) The nature of content delivery through Instagram as it is characterized with a great deal of interaction that led to absence of differences that may be due to the impact of the difference of visual stimuli, due to the student easy dealing with the content, either stimuli are real or graphical, in this case we can see that the greatest impact was the nature of the Instagram regardless of the visual stimuli type.

(E) The visual stimuli (real - graphical) provide a solution the knowledge burden theory, one of its principle is the (Attention Focus Principle) which pays attention to changing the traditional education and learning designs that lead to attention absence between different sources of information due to their heavy burden on the working memory. The design of information as an integrated unit including a written or visual stimuli illustrates the text content, is understandable more than the design which is based on the division of educational content into two parts that spatially separate (text and visual stimulus), the matter characterizes the visual stimuli where information can be designed as one unit enabling the student to interact with the educational content leading to learning improvement.

This finding was in harmony with what suggested by the previous studies and researches in the field of the use of visual stimuli in the achievement of the cognitive aspects, one of these studies is the one prepared by Grabowski, 2004)), Joseph (2006), Fath Allah (2007), Hughes, 2007)), (Stavy, 2008), (Tibell, 2010), whereas this research finding differs with that of finding of Al-Sarraf (1998), and Khalaf Allah (2010).

\section{Recommendations}

In the light of the findings, the following recommendations are suggested: 
12.1 Taking advantage of the visual stimuli (real - graphical) in the presentation of the different courses, due to its good interactive and attract the attention of students.

12.2 Using different types of visual stimuli other than the photos in photo-sharing sites such as the video clips, graphical photo and maps for high school students.

12.3 Encouraging faculty members to use of visual stimuli (real - graphical) and establishing educational accounts in Instagram helping them in both teaching and learning processes and interaction.

12.4 To study the relationship between different types of visual stimuli in photo sharing with other grades, and assess their impact on many of the dependent variables.

12.5 Conducting further studies that discuss the impact of visual stimuli in photos sharing sites on other educational programs.

\section{References}

AbdulHadi, Mohammed Abdulrahman, \& Abdul-Hafith Mohammed. (2004). A comparative study for using the graphical photos in the social and science studies by the preparatory students - faculty of education magazine Tanta university -December.

Abu Gamar, \& Amal Mutwali Ibrahim. (2011, April 13-14). The importance of visual photo for theatre students at the quality education establishments in Egypt, presented at the sixth yearly Arabic scientific conference and the third one worldwide - Egypt, pp155-179.

Akpinar, E., \& Ergin, O. (2008, June). Fostering Primary School Students' Understanding of Cells and Other Related Concepts with Interactive Computer Animation Instruction Accompanied by Teacher and Student-Prepared Concept Maps. Asia-Pacific Forum on Science Learning and Teaching, 9(1), 10. Hong Kong Institute of Education. 10 Lo Ping Road, Tai Po, New Territories, Hong Kong.

Al-Amoudi, Ghada Abdullah (2009). Social softwares in the education used in the social networking as a form" a paper raised in the first international conference for electronic learning and distance education - Saudi Arabia Riyadh.

Al-eraimia, \& Badria Nasser Mohammed. (2011, Dec.), the tools of the electronic communication. Educational Development Magazine, Omman Sultunate, 1-15.

Al-Hadlaq, \& Abdullah Abdul-aziz. (2012). The good educational computer software specifications under viewpoint of the Saudi educators and designing a form of assessment. King Saudi University Magazine, 4, 432-463.

Al-Halfawi, \& Waleed Salim. (2009). Design of electronic education system based on some web applications 2.0 and its effectiveness in the development of the cognitive achievement and creative thinking toward its use by the education technology students. Studies and Researches, Cairo, Egyptian society of education technology, 19(4).

Al-Hasri, \& Ahmed Kamil. (2004). The explanatory figures reading and to which extent they are available in the imaged questions in the preparatory science exams books. Scientific Education Magazine, Egypt, 15-17.

Al-Hindawi, \& Ali Faleh. (2005). Development psychology. Al-Ain, University Book House.

Al-Jazzar, \& Nagafa Gotb. (1994). Assessing the skill for reading the photos included in the history books by the high school first class. Curriculum and Teaching Methods, Egypt 29.

Al-Galabi, Sawsan. (2005). The fundamentals of building psychological and educational tests\& measurements. Damascus, Ala'a Al-din house.

Al-Khalifa, \& Hind Sulaiman. (2006, Dec. 2-6). Web 2.0 techniques utilization in the education and electronic training service. Presented to the $4^{\text {th }}$ Saudi technical conference for vocational training, Riyadh.

Al-Omary, \& Aysha Balheesh Al-Jazzar. (2012). Educational means and material. Riyadh, Al-Roshd library.

Cobb, J. (2008, December). E-learning 2.0 for associations Learning. Retrieved December 20, 2014, from http://www.tagoras.com/learning20/.

Computer and information technology. (2015). Riyadh, ministry of education, Hamid Mohammed Abdul Maqsoud Abdullah (2004), development of the visual stimuli in the hearing-impaired students from the viewpoint of the students and teachers. Educational and Social Studies, Egypt (2004) 449-452.

Environment. Nursing Clinics of North America, 43(4), 575-582. 
Fath Allah, \& Mohwar Abdul-Salam. (2007). The effect of interaction between the graphical photos and the cognitive style on the achievement, applied on the fifth grade science book. Gulf massage- Saudi Arabia pp.47-114.

Grabowski, B. (2004). The Effects of Various Animation Strategies in Facilitating the Achievement of Students on Tests Measuring Different Educational Objectives. Association for Educational Communications and Technology, 27th, Chicago, IL, October 19-23.

Hochman, N., \& Schwartz, R. (2012, May). Visualizing Instagram: Tracing cultural visual rhythms. In Proceedings of the Workshop on Social Media Visualization (SocMedVis) in conjunction with the Sixth International AAAI Conference on Weblogs and Social Media (ICWSM-12), pp. 6-9.

Hu, Y., Manikonda, L., \& Kambhampati, S. (2014). What we Instagram A first analysis of Instagram photo content and user types. Proc. AAAI ICWSM.

Khalafullah, Mohammed Jabir. (2010). Visual stimuli density difference effectiveness (reality - symbolism) recently presented in the Internet in the presentation of library education proposal program for the preparatory students. Al-Azher University, pp. 131-194.

Khamis, Mohammed Atia. (2003). Education technology processes, Cairo, Dar Al-kalma house. Dosougi, Mohammed Ibrahim (19-20 2006):technological innovations and their impact on the learning and education environment. Presented to the $4^{\text {th }}$ yearly conference - talented and gifted discovery in the Arabic world-Egypt, pp. 455-508.

Klopfer, E., Osterweil, S., Groff, J., \& Haas, J. (2009). Using the technology of today, in the classroom today. The instructional power of digital games, social networking, simulations, and how teachers can leverage them. The Education Arcade, 1-21.

Kucuktunc, O., Sevil, S. G., Tosun, A. B., Zitouni, H., Duygulu, P., \& Can, F. (2008). Tag suggestr: Automatic photo tag expansion using visual information for photo sharing websites. Semantic Multimedia, Springer Berlin Heidelberg, 61-73.

Marbach-Ad, Gili, Rotbain, Yosi, \& Stavy, Ruth. (2008). Using Computer Animation and Illustration Activities to Improve High School Students' Achievement in Molecular Genetics. Journal of Research in Science Teaching, 45(3), 273-292.

Mostafa, Akram Fathi. (2006). Educational Internet site production - educational contemporary vision and patterns. Cairo, Al-Kotob House.

Nov, O., \& Ye, C. (2008). Community photo sharing: Motivational and structural antecedents. ICIS 2008 Proceedings, 91.

Othman, Mostafa Sayed, \& Othman, Omnai Sayed. (1994). A vision in learning using the small technologies. Cairo, Roz Al-Yousif Printing Press.

Paivio, A. (2006). Dual coding theory and education. Ponenciapresentadaen: Pathways to Literacy Achievement for High Poverty Children, University of Michigan. Retrieved December 20, 2014, from http://www.umich.edu/ rdytolrn/pathwaysconference/pathways. html.

Ra, M. R., Govindan, R., \& Ortega, A. (2013, February). P3: Toward Privacy-Preserving Photo Sharing. In NSDI pp. 515-528.

Rundgren, C. J. A., \& Tibell, L. (2010). Critical Features of Visualizations of Transport through the Cell Membrane: An Empirical Study of Upper Secondary and Tertiary Students' Meaning-Making of a Still Photo and an Animation. International Journal of Science and Mathematics Education, 8(2), 223-246.

Sadig, Amal, \& Abu Hatab. (1996). Educational psychology. Anglo Libraray.

Schlosser, P. A. (2010). Pedagogical Praxis Surrounding the Integration of Photography, Visual Literacy, Digital Literacy, and Educational Technology into Business Education Classrooms A Focus Group Study. Doctoral dissertation, University of Minnesota.

Shawgi, Ismail. (2007). Cairo (2003): building a system to present the curriculum through the Internet and the relevant impact on the student in the networking-dependant learning. Doctorate dissertation, Halwan University, Egypt. 
Shepl, Isam Shawgi, Zidan, Ashraf Mohammed/Mobariz, Manal Abdul A’al/Khatir, Saeeda Abdul-Salam/ Rabea, \& Hanan Mohammed. (2013). Elementary school teachers on-service training needs, including dealing with the printed and electronic visual stimuli: education technology - studies and researches - Egypt, pp.1-57.

Steiner, T., Gabarró, J., \& Hausenblas, M. (2014). Enriching unstructured media content about events to enable semi-automated summaries, compilations, and improved search by leveraging social networks. Doctoral dissertation, PhD thesis, UniversitatPolitecnica de Catalunya.

Stokes, S. (2002). Visual literacy in teaching and learning: A literature perspective. Electronic Journal for the integration of Technology in Education, 1(1), 10-19.

Taylor, M., Duffy, S., \& Hughes, G. (2007). The use of animation in higher education teaching to support students with dyslexia. Education \& Training, 49(1), 25-35.

The Herridge Group. (2004). The Use of Traditional Instructional Systems Design Models for eLearning. Retrieved 8 ,

2015 , from http://www.herridgegroup.com/pdfs/the\%20use \%20of\%20traditional\%20isd\%20for\%20elearning.pdf

Waycott, J., \& Kennedy, G. (2009). Mobile and Web 2.0 technologies in undergraduate science: Situating learning in everyday experience. Same Places, Different Spaces. Proceedings of the Australasian Society for Computers in Learning in Tertiary Education 2009, 1085-1095.

Weller, M., \& Dalziel, J. (2007). Bridging the gap between web 2.0 and higher education. Pratical Benefits of Learning Design, 76-82.

Yeh, H. T. (2008). Visual literacy: An investigation of how pre-service teachers interpret and analyze instructional visual materials. Doctoral dissertation, University of Northern Colorado.

Younis, Mohammed Ibrahim. (1999). Computer and information technology-dependent education, Education Technology Magazine, Cairo. 